36 Literatura e Sociedade

\title{
0 REALISMO UTÓPICO DE Charles Dickens
}

\section{Daniel Pugla}

Universidade de São Paulo

\section{Resumo}

Um dos aspectos mais notáveis dos romances de Charles Dickens é a intenção de abarcar a totalidade da vida cotidiana. Com resultados desiguais, mas sempre interessantes, tal elaboração artística acaba por formular uma crítica contundente à racionalidade prática e à desigualdade presentes na sociedade vitoriana. Esse diagnóstico, no entanto, tem um caráter peculiar: as instituições e estruturas sociais devem ser transformadas pela pureza do amor e da inocência, num impulso ao mesmo tempo utópico e regressivo.

\section{Abstract}

One of the most remarkable aspects of Dickens' novels is his effort to depict the totality of daily life. Though flawed at times, but always interesting, these descriptions contained a sharp criticism of the pragmatism and inequality present in Victorian society. There is, however, a peculiar aspect of Dickens' social vision: for him, social structure and institutions could only be transformed through the purity of love and innocence, a belief which is at the same time utopian and regressive.

\section{Keywords}

Charles

Dickens;

english novel; history. 
ombey e Filho (1848) foi o sétimo romance de Dickens e possivelmente atuou como um divisor de águas em sua obra: a crítica social, a observação dos costumes e o diagnóstico da época passariam a ser, daí em diante, mais mordazes e contundentes. Nessa obra o narrador dickensiano formalizava os paradoxos da sociedade inglesa em meados do século XIX, elaborando soluções estéticas para contradições da realidade. Em consequência, uma poderosa rede de pressupostos críticos e de concepções sobre a própria época era mobilizada nos detalhes do tecido narrativo. Para leitores do século XXI, o possível interesse em desentranhar tais debates talvez resida na permanência de muitas das contradições tanto estéticas quanto históricas daquele período, bastante revigoradas desde então.

Como linhas bastante gerais, o enredo de Dombey e Filho traz a história do inflexível e rigoroso Mr. Dombey, obcecado pelo desejo de ter um herdeiro para sua empresa, a Dombey e Filho, ao mesmo tempo em que ignora e despreza sua filha, Florence. O romance começa com o nascimento de seu filho, Paul, e a morte de Mrs. Dombey logo após o parto. O menino é visto quase que exclusivamente como um novo parceiro nos negócios, centro das atenções de Mr. Dombey. O nome do próprio romance já é repleto de significados e entroncamentos, pois designa uma relação que é concomitantemente empresarial e familiar, numa nota de ambivalência que reverbera continuamente ao longo da trama. Por fim, teremos uma punição exemplar do gerente-geral Carker e todas as peripécias terminarão com o resgate celebratório do amor entre o pai e a filha anteriormente rejeitada, demonstrando, entre outras mensagens de cunho moralizante, que uma família não deve ser gerida como um entreposto comercial.

Durante todo o romance o narrador opera de um modo particular, não raro contraditório: por meio de seus procedimentos de quebra e justaposição de cenas e comentários, parece querer a um só tempo apreender e ocultar certos conteúdos que afloram a partir do funcionamento da sociedade que tem diante de si. Nessa linha tênue entre desvelar e encobrir, realiza um de seus grandes méritos, que é a demonstração das múltiplas conexões e determinações de uma intrincada trama 
social. Visto como totalidade, na visão de seus vários episódios constituintes, Dombey e Filho não culpabiliza quaisquer personagens isoladamente, de modo que sua investigação tenta averiguar vínculos e simbioses de vasta abrangência e alcance. Ainda assim, a execução final do vilão Carker, atropelado por um trem, surge como um traço melodramático incômodo e que merece ser mais bem investigado, quase o espasmo de um narrador que reluta em aceitar as consequências finais de seu diagnóstico: a constatação de que os processos sociais e subjetivos têm causalidades e explicações multiformes, sem espaços para esquemas ou reduções maniqueístas. Ou seja, o narrador faz um mapeamento e, a despeito de si próprio, consegue estruturar em forma literária uma previsão: a de que conflitos latentes por fim acabarão emergindo e, para evitá-los ou solucioná-los, de nada adianta a simples nomeação de heroísmos ou vilanias individualizadas, sem contextos ou mediações.

Vale lembrar, entre outros fatores, que a escrita de Dombey e Filho acontecia nos meses anteriores aos conflitos e revoltas de 1848 na Europa, os quais, como antevisto pelo romance, seriam abafados pelo uso da força e da violência. Ocorre que, sendo ponto de inflexão na estética dickensiana, o narrador de Dombey e Filho conserva e retrabalha estratégias anteriores enquanto formula novos caminhos. Daí a possibilidade de que o sacrifício final do vilão seja um recurso remanescente do melodrama, um recurso um tanto quanto artificial e utilizado num romance cuja matéria social, felizmente, acaba por se impor. Se estivermos corretos, é provável que essa solução um tanto quanto desajeitada, de purgar os males por meio de uma punição exemplar, seja uma tentativa de achar um antídoto momentâneo para um conjunto de problemas interligados ao longo da trama. Em virtude disso, o que pode estar em processo não é apenas o encontro de um escritor com sua maturidade criativa, mas, sobretudo, a cartografia de um sistema de relações em que tudo passava a ser mercável, em que uma empresa familiar já podia ser utilizada para vislumbrar um princípio de organização: de um país, de um império, de um modo de dominação social. Nessa dinâmica, um segredo começava a ser intuído: o de que na base de tal dominação se encontrava um discurso que negava a opressão enquanto a exercia, que fazia da Inglaterra um império - ao preço de, internamente, subjugar a maior parte de sua população e, externamente, violar em termos culturais e materiais suas colônias. Portanto, denunciar e simultaneamente justificar tal sistema de forças acaba sendo a dança e contradança desse narrador, que na sua coreografia pode aprender seu passo fundamental: entender de que maneira o discurso de uma cultura regida por laços econômicos poderia ser a pista enigmática, a ponta do iceberg de uma forma hegemônica de organizar a vida social. Isso necessariamente trazia à tona, não sem resistências, um grande contingente de pessoas cujas vozes eram silenciadas - nas colônias e nas fábricas, nas ruas e nos lares. Ao fim e ao cabo, no entrecho dickensiano essa combinação de império próspero e usurpação social caminha sob um disfarce: o estigma da conciliação.

2

Nos escritos de Dickens o trabalho, a atividade laborativa do ser humano, surge sob a marca da dualidade: de um lado, com nota positiva, numa oposição ao ócio dos desocupados e malandros; de outro, com nota negativa, quando oposto ao 
divertimento e fruição. Evidentemente estão presentes aqui juízos morais, em seu tanto de abstrato e descolados das condições materiais em que o trabalho se efetiva. A bem da verdade, a rotina mecanizada, destituída de sentido, que transforma seres humanos em autômatos cumpridores de tarefas: isso surge na obra dickensiana como clara decorrência da Revolução Industrial. Entretanto, se reconhece o estatuto escorchante imposto cotidianamente pelo modo de produção capitalista, Dickens coloca como contraposição a necessidade da fantasia, de uma certa esfera lúdica que iria mitigar essa situação calamitosa - nesse ponto, basta lembrarmos de Tempos difíceis (1854) e a maneira como o utilitarismo e o sistema educacional são criticados por embotarem aquilo que seria o livre curso da imaginação. Por outro lado, essa aparente dicotomia simplificadora em relação ao trabalho acaba por tangenciar o incandescente da exploração, para além do véu que a mantém encoberta e disfarçada. Em outros termos, os apelos em prol dos livres andamentos da fantasia - regressivos se tomados como objetivo final - são certamente um ponto avançado na denúncia da vida transformada em mercadoria, quando os saltos do imaginário e do devaneio são permitidos, mas desde que sob a vigilante tutela econômica. Assim, no momento em que Dickens defende os poderes da imaginação, acaba por denunciar o aprisionamento ao qual a fantasia humana está submetida. Não identifica todos os elos formadores desse cárcere, mas mostra que as correntes existem. Nesse sentido, os méritos de sua obra nesse capítulo, ainda que insuficientes, não são poucos - principalmente se lembrarmos o enorme peso ideológico que o elogio ao trabalho possuía dentro da moralidade vitoriana, uma pregação profundamente enraizada no puritanismo das classes médias ascendentes. Em meados do século XIX, quando Dombey e Filho estava sendo escrito, a glorificação do trabalho havia adquirido ares de mandamento inquestionável. Matthew Arnold, por exemplo, gostava de citar o seguinte preceito: "Trabalhar. Não nisto ou naquilo - mas, Trabalhar". Ou ainda o eminente Cardeal Newman: "Todos que respiram, ricos e pobres, educados e ignorantes, têm uma missão, têm um trabalho". ${ }^{1}$

O trabalho sem qualificadores, flanando num mundo ideal, no modo referido por Arnold, ou como missão edificante, de conciliação das diferenças, na asserção de Newman: esse realmente parece ser o paradisíaco horizonte da labuta purificada. Para os que sentavam nas almofadas da injustiça e não tinham de respirar o ar das minas, adoecer nos teares ou esgotar-se como serviçais, realmente nada era mais fascinante que o trabalho, pois a contemplação distante permite o elogio eloquente. Por seu turno, com a costumeira ambiguidade que o caracteriza, Dickens reconhece que esse trabalho pode não apenas dignificar, mas também destruir os seres humanos. Assim, existe uma certa obsessão, na sua obra como um todo, por apresentar os modos pelos quais seus personagens ganham suas vidas, de que maneira retiram seu sustento, num verdadeiro compêndio e catálogo de profissões, ocupações e afazeres. A criação de valores, a geração da riqueza, bem como o metabolismo entre seres humanos e natureza, passam todos a ser observados sob um ponto de vista material, em que a divisão social do trabalho adquire contornos determinantes.

\footnotetext{
${ }^{1}$ Essas citações aparecem em W. E. Houghton, The Victorian Frame of Mind 1830-1870, New Haven, Yale University Press, 1957, p. 243-4.
} 
Em alguma parte de As aventuras de Tom Sawyer (1876), o norte-americano Mark Twain escreve que o trabalho seria tudo aquilo que uma pessoa é obrigada a fazer e o passatempo seria tudo aquilo que uma pessoa não é obrigada a fazer. Até certo ponto isso poderia ser aplicado à cisão que Dickens estabelece entre atividade produtiva e divertimento, entre tarefas e fruições. Ocorre que para o escritor inglês a dicotomia apresenta impurezas, os limites são quebrados e a dinâmica que surge é a de uma realidade avassaladora: mais e mais todo o tempo livre, qualquer passatempo, tudo vai sendo tomado pela esfera do trabalho. A maioria dos personagens passa a ter uma profissão e é nesse sentido que o gerente-geral Carker é um exemplo ilustrativo desse perfil. Não por acaso, ele também irá corporificar os novos impulsos de modernização e progresso da sociedade vitoriana, impulsos esses que trazem em si toda uma série de desventuras que parecem minar e relativizar a própria ideia de modernização e progresso.

Nesse novo mundo pleno de profissionais assalariados, dos mais humildes aos mais abastados (caso de Carker), os personagens dickensianos que recebem as mais severas críticas são aqueles que não trabalham, os diletantes como Henry Gowan, de Pequena Dorrit (1857), os aristocratas egoístas como Sir Mulberry Hawk, de Nicholas Nickleby (1839), ou os parasitas como Harold Skimpole, de Casa soturna (1853). Por outro lado, a profusão de empregados e serviçais domésticos que desempenham papéis relevantes nos entrechos dickensianos é notável, ${ }^{2}$ cabendo lembrar que pela própria natureza da Dombey e Filho - ou seja, uma gigantesca empresa de raiz familiar e ao mesmo tempo uma família administrada como uma empresa -, Carker surge como uma síntese de todo um universo de empregados de escritório e serviçais domésticos, que em teoria mereceriam o elogio do narrador, sempre em contraposição aos que não trabalham. Contudo, nesse caso, o traiçoeiro gerente serve como alegoria da ameaça representada pelas classes laboriosas, em consonância com uma percepção que passava a vicejar em muitos setores da elite vitoriana: os trabalhadores assalariados eram vistos, grosso modo, como uma massa perigosa, por vezes incontrolável, e o temor que causavam era apenas tolerado em virtude do reconhecimento do quanto a atividade econômica era dependente deles. Eram vistos como fundamentais, porém detentores de uma força que, em revolta, poderia modificar de maneira inédita a realidade do período. Nesse sentido, muitos chegavam a comparar o potencial benéfico e maléfico dos trabalhadores assalariados ao mesmo poder que começava a ser atribuído a uma outra grande novidade da época: as ferrovias.

\section{3}

Após a morte de seu filho, o pequeno Paul, Mr. Dombey viaja de Londres a Birmingham e compara a ferrovia à própria força triunfante da morte. Está de luto, vivendo uma introspecção que é apresentada aos leitores numa surpreendente novidade, consideradas suas parcas demonstrações de vida interior até então. Mas o narrador avança e ilustra um mal-estar que sugere conexões amplas, para

\footnotetext{
${ }^{2}$ P. Horn, The Rise and Fall of the Victorian Servant, Gloucestershire, Sutton Publishing, 1997.
} 
além do drama sofrido pelo protagonista. A modernidade é vista pelos olhos de Mr. Dombey e os ritmos do trem são registrados quase como sendo a pulsação da morte, algo implacável e incompreensivel: "objects close at hand and almost in the grasp, ever flying from the traveller, and a deceitful distance ever moving slowly with him: like as in the track of the remorseless monster, Death!". ${ }^{3}$ No entanto, todos os elementos configuram um conjunto de objetos e coisas sob a influência de mãos demasiado humanas: a máquina do progresso serve para que Mr. Dombey viva seu luto, mas num mundo forjado pelo trabalho social. ${ }^{4} \mathrm{Ou}$ seja, a revelação dos conflitos internos do protagonista acontece num movimento de contradição interna da própria modernidade, em que os traumas subjetivos estão sendo remodelados de acordo com um contexto que determina a necessidade de uma nova experiência psíquica. Até certo ponto, o encadeamento e o fluxo das palavras sugerem a entrada do narrador em uma nova seara: a de uma psicologia preocupada em demonstrar a reificação e os sacrifícios aos quais Mr. Dombey está submetido. ${ }^{5}$ A linguagem mimetiza os inexoráveis ritmos do trem - "Away, with a shriek, and a roar, and a rattle, from the town, burrowing among the dwellings of men and making the streets hum" - e a máquina é comparada quase que a um animal que serpenteia, rugindo e chocalhando, numa poderosa síntese em que a violência do mundo natural empresta seus atributos para que seja efetivada a subjetivação do mundo industrial. Os sofrimentos de Mr. Dombey são descritos por um método que, como um todo, tenta combinar os efeitos imediatos da velocidade sobre a visão e a audição com um ágil caleidoscópio de cenas e quadros vertiginosamente expostos - tudo isso sob o sugestivo influxo da argamassa dos contrastes sociais: "The power that forced itself upon its iron way - its own - defiant of all paths and roads, piercing through the heart of every obstacle, and dragging living creatures of all classes, ages, and degrees behind it, was a type of the triumphant monster, Death". ${ }^{7}$

O narrador deixa transparecer todos os pavores e todos os encantos que a modernidade corporificada nas ferrovias causava numa época atordoada pelo impacto das recentes forças produtivas. O desenvolvimento de tais forças, entretanto, deixa entrever o caráter caótico da nova economia: dinâmica e inovadora, porém insaciável e voraz. Contudo, fazer a conexão da morte com uma máquina que simbolizava a nova ordem também desloca o medo indeterminado do futuro e

C. Dickens, Dealings with the firm of Dombey and Son - wholesale, retail and for exportation, London, Penguin, 1985, p. 354 ["objetos tão próximos que quase podem ser tocados, e que sem cessar escapam ao viajante, enquanto um enganoso horizonte se move lentamente nele: como numa trilha desse monstro impiedoso, a Morte!" - tradução nossa].

${ }^{4}$ I. Milner, "The Dickens Drama: Mr. Dombey", Nineteenth-Century Fiction, v. 24, p. 477-87, 1970.

${ }^{5}$ D. Rainsford, Authorship, Ethics and the Reader: Blake, Dickens, Joyce, Houndmills, Macmillan, 1997, p. 127-37.

${ }^{6}$ Dickens, Dealings with the firm of Dombey and Son, op. cit., p. 354 ["Avante, bradando, rugindo, chocalhando, partindo da cidade, escavando seu caminho por entre as moradias dos homens e fazendo vibrar as ruas" - tradução nossa].

${ }^{7} \mathrm{Idem}$,ibidem ["A poderosa força que arrastava todo o comboio sobre a via férrea, desafiadora de todos os caminhos e estradas, mergulhando no coração de cada obstáculo, e arrastando atrás de si criaturas de todas as classes, idades, e condições, era uma manifestação do monstro triunfante, a Morte" - tradução nossa]. 
focaliza as possibilidades palpáveis de mudança, ou seja, não apenas e tão somente um pavor metafísico diante do desconhecido, mas uma inquietação fundada em condições materiais. Tais condições, uma vez compreendidas, podem servir para que algum controle seja estipulado, para que alguma ordem seja estabelecida - e talvez não seja exagero sugerir que o potencial destruidor da ferrovia será domesticado quase ao final do romance, quando ela será utilizada para o aniquilamento de Carker: a máquina como espada da justiça.

Após a viagem de trem em que Mr. Dombey vive o luto pela perda de seu filho, e portanto vê frustrados seus planos sucessórios para a empresa, o romance desenvolve um terreno constantemente movediço, com sua filha Florence sendo forçada a abandonar a casa paterna, com o casamento fracassado de Mr. Dombey e Edith e, não menos importante, com o gerente-geral Carker dilapidando a Dombey e Filho em proveito próprio: tudo isso numa sôfrega sucessão de infortúnios que realça e desenvolve o aturdimento causado pela viagem de trem. Para Mr. Dombey a ferrovia talvez apareça quase como a tecnologia mitificada, carregando-o para um universo de visões reprimidas, em que a morte e a finitude respondem como anteparo, bastante precário, às ilusões perdidas: suas, de sua classe, de sua época. No entanto, o narrador utiliza tal aturdimento também para trazer à tona novos aspectos de uma realidade complexa, diluindo as rígidas separações entre o individual e o social, o particular e o geral. Esse diagnóstico é o inventário de violências amealhado pelo narrador, numa rede de conexões em que o peso estrutural do sistema rompe as fronteiras entre dilemas individuais e impasses coletivos, também aniquilando o envoltório das soluções isoladas em meio ao caos universal. Desse modo, a morte do pequeno Paul é a morte do herdeiro e também a alegoria das várias mortes exigidas no altar da acumulação - que arrasta "living creatures of all classes, ages, and degrees behind it". ${ }^{8} \mathrm{E}$, nesse sentido, a morte de Carker é particularmente relevante.

\section{4}

A eliminação do gerente-geral serve como sintomática advertência. Esse vilão dickensiano foi possivelmente o primeiro grande representante dos escalões de supervisão e administração na ficção britânica. ${ }^{9}$ Nas classes dominantes da era vitoriana, começava a surgir uma certa inquietação no que se referia a essa camada gerencial, no leque que ia desde os diretores da mais alta patente até os supervisores mais rasos, todos representantes de um mal necessário para o estabelecimento da nova hierarquia profissionalizada no mundo dos negócios. A consolidação de uma faixa de funcionários posicionada entre capitalistas e proletários parecia trazer embutido mais um ingrediente de desafio ao predomínio dos donos dos meios de produção. E de certo modo isso era baseado numa verdade empírica: os gerentes possuíam um conhecimento mais completo e preciso acerca do que acontecia nos locais de trabalho. Tal diferença em relação à quantidade de informação e experiência, resultado

\footnotetext{
${ }^{8}$ Idem, ibidem ["arrastando atrás de si criaturas de todas as classes, idades, e condições" - tradução nossa].

${ }^{9}$ R. B. Henkle, Comedy and Culture: England 1820-1900, Princeton, Princeton University Press, 1980, p. 111-84.
} 
prático da divisão das tarefas, fornecia as bases para os conflitos de poder, ou seja, a cisão entre empregadores e gerentes deixava espaço para que fossem questionados deveres, responsabilidades e autoridades - numa reverberação que deixava mais explícita a contradição interna do sistema: a separação entre os que apenas possuíam sua força de trabalho e os que possuíam os meios para que tal força fosse efetivada. Contrariamente aos proletários, os níveis gerenciais recebiam dados mais abrangentes sobre o processo de trabalho, o que lhes dava elementos adicionais para compreender os bastidores e a lógica dos interesses em conflito. Além disso, ao mesmo tempo em que eram polias e roldanas no mecanismo para disciplinar os demais subordinados, os gerentes estavam eles próprios sujeitos ao regime de vigilância e obediência. Assim, o narrador de Dombey e Filho aborda tais contradições ao escolher um gerente-geral de uma empresa mercantil, ainda mais se considerarmos que no ambiente dos escritórios as discrepâncias ficavam bastante evidentes e pronunciadas: em última instância, os empregados administrativos nada mais eram que trabalhadores assalariados, embora a distância do chão das fábricas criasse uma certa ilusão de superioridade. Por outro lado, a escolha de Carker e também seu sacrifício em rito sumário dão pistas de algo mais: os gerentes e o universo administrativo entraram conjuntamente no imaginário do século XIX - e essa ligação não foi casual, uma vez que os escritórios vitorianos espelhavam e produziam as ambiguidades institucionais do próprio papel dos gerentes. ${ }^{10}$

O dilema que passava a afligir os detentores das rédeas econômicas era: até que ponto seria prudente delegar poder e autoridade para esse novo rebanho gerencial, um rebanho dado a estripulias e com perigosas tendências a ter vontade própria? A resposta do narrador de Dombey e Filho a tal dilema não poderia ser mais categórica: Carker não havia sido nada confiável e Mr. Dombey, ao confiarlhe o poder, viu-se praticamente destituído de quaisquer funções, como se um novo arranjo na organização do trabalho pudesse estabelecer novas relações de produção, pudesse quebrar linhas hierárquicas enrijecidas. As conclusões, se levadas às últimas consequências, eram perturbadoras. Assim, o narrador evita questionar a autoridade do proprietário, a organização dos escritórios, as instituições: tenta localizar a nota desafinada num indivíduo, em Carker, mantendo as portas abertas para que outros funcionários, cordatos e subservientes, fizessem bom uso das estruturas estabelecidas. No conhecido comportamento do narrador, vão sendo registradas as instabilidades e inseguranças do progresso vitoriano, mas ao mesmo tempo tentando manter a validade de suas instituições socioeconômicas. Em decorrência disso, Carker vira bode expiatório porque com suas tramoias e negociatas escusas acabara mostrando a nudez do sistema: o dinamismo do mercado, o poder prevalente do dinheiro, a modernidade avassaladora - tudo isso aparecia como novo reino da liberdade, mas todos os caminhos estavam bastante predeterminados de acordo com interesses de grupos específicos. Carker não podia vencer no mundo das carreiras aparentemente abertas ao mérito: seus limites na hierarquia eram aqueles dados aos trabalhadores assalariados, num jogo com regras já

${ }^{10}$ D. Lockwood, The Blackcoated Worker: A Study in Class Consciousness, Oxford, Clarendon, 1989, e também G. Anderson, Victorian Clerks, Manchester, Manchester University Press, 1976. 
anteriormente definidas. Porém, também tais predeterminações começavam a escapar ao controle dos grandes proprietários, como vimos em Mr. Dombey no seu pasmo sobre os trilhos da modernidade. Desse modo, era mister retomar o controle, mostrar afinal que o mundo da livre iniciativa não era o mundo em que todas as iniciativas eram livres. Em decorrência disso, e na contracorrente do intricado mapeamento de relações que estabelecera ao longo do romance, o narrador tenta preservar a moldura do sistema e centraliza os problemas em Carker. As distorções ocorreriam no nível individual, nas sutilezas das falhas morais e dos tropeços de caráter. Com a punição exemplar de Carker, estraçalhado por uma locomotiva, o narrador principia a curva ascendente para o término do romance em chave de júbilo, no estabelecimento esfuziante de uma paz reencontrada.

\section{5}

A interdependência entre jugo econômico e conflitos latentes alcança em Dombey e Filho um momento central na obra de Dickens - e que nos ajuda a entender alguns caminhos históricos. Se em seus romances iniciais a importância dada ao poder econômico já aparecia de modo marcante, a abordagem do universo das finanças ainda era feita por meio de um enfoque particularizado, ou seja, normalmente um usurário, pessoa com posses mas de má índole, e responsável por todas as mazelas e desgraças na trama. Nesse sentido, em Nicholas Nickleby (1839) e Loja de antiguidades (1841) surgem os sentimentos de veio moralizante, com a usura sendo condenada por permitir que pessoas ganhem dinheiro sem ter de trabalhar. Contrariamente a isso, os ricos benévolos eram retratados como uma classe que tinha, em algum momento no passado, trabalhado para adquirir seus bens. Mas nessa altura da obra dickensiana todos os contrastes e as rígidas divisões entre bons e maus são retratadas fundamentalmente em nuance de leveza cômica - e talvez isso possa ser dito até Martin Chuzzlewit (1844). Nas Aventuras de Mr. Pickwick (1837), por exemplo, existe como que um equilíbrio idealizado entre os diferentes agrupamentos de personagens ao final do romance. Em Oliver Twist (1839) uma crítica mais severa começa a ser feita, principalmente quando a gangue dos ladrões mirins serve como imitação, em tom de chacota, das maquinações e das ideias firmemente aceitas nas esferas de poder inglesas: com humor, às vezes soturno, o discurso da hipocrisia imperial é caricaturizado pelo modus operandi da quadrilha dos garotos - mas as conexões não são imediatas, prevalecendo uma ordem confiante nos bons desígnios de uma nação que, em última instância, promoveria o pacífico convívio entre todos os seus cidadãos. Por outro lado, é certo que já em Nicholas Nickleby (1839) existe uma primeira tentativa de dar forma ao heroísmo de um jovem gentleman, que quer construir sua trajetória como realização do mito individualista, de alguém que, por supostas qualidades pessoais inquestionáveis, merece ter sob seu comando serviçais, mulheres e crianças. Todavia, isso ainda não conforma as principais linhas de força na obra dickensiana do período.

Mas o que já se anunciaria, parcialmente, em Martin Chuzzlewit, seria adensado, e agora formalizado no romance seguinte, Dombey e Filho. Ou seja, o ordenamento social europeu, que tinha na Inglaterra um de seus pilares de sustentação, estava prestes a ser convulsionado por crises econômicas e levantes populares, algo que teve impacto nas elaborações artísticas do período. A partir do que emergira em 
Dombey e Filho, isto é, a percepção de que a prosperidade inglesa e europeia precisava ser mantida com mãos de ferro, uma nova época na vida do continente determina um novo enfoque para os romances dickensianos. O poder financeiro deixa de ser visto apenas sob a lupa individual para ser analisado como fenômeno sistêmico, ainda que com eventuais recaídas, como no caso da culpa individualizada em Carker. De todo modo, podemos ver que em Pequena Dorrit (1857), Grandes esperanças (1861) ou Nosso amigo comum (1865), os destinos dos personagens, os desdobramentos dos enredos e a perspectiva narrativa mantêm uma estreita simbiose com os ritmos e compassos dados pelo poderio econômico de nações e culturas em disputa - poderio esse que nunca tem seus mistérios de origem ou funcionamento completamente esclarecidos. O que havia sido visto como vilania agora passava a ser despersonalizado, às vezes encarnado nas bolsas de valores, outras vezes em intrincados conglomerados de investimento e financiamento. Em sua refração estética, o espírito dos novos tempos tornava cada vez mais difíceis os finais felizes oriundos da simples mudança no coração de indivíduos arrependidos. Desse modo, num romance como David Copperfield (1850), ainda aparece como tentativa, ao menos na superfície, a criação de um universo das classes médias que podem vencer pelo esforço: surgia uma vez mais a quimera do triunfo individual em meio à vasta arena de conflitos econômico-sociais. Ocorre que, já em torno da própria saga de David, ficarão estabelecidos os desencaixes entre prosperidade e destituição, seja na metrópole, seja nas colônias do império. Tudo isso ficará ainda mais acentuado em Grandes esperanças, quando a imagem do projeto nacional não resiste à contraprova de todos aqueles que são deixados nas sombras do imperialismo inglês - e que a qualquer momento podem retornar e apenas exigir seu direito de voz. Entretanto, tudo isso é parcialmente dissimulado pelo narrador, numa lição talvez aprendida desde Dombey e Filho.

Retornando ao nosso ponto de partida, vemos que a tensão para conciliar contradições faz que o narrador de Dombey e Filho seja, sob certa perspectiva, um precursor dentre os narradores dickensianos. Se, por um lado, tal narrador parece ser um patriarca, talvez apenas um pouco menos despótico que o próprio $\mathrm{Mr}$. Dombey, por outro, sua galeria de personagens é construída como um quebracabeças esclarecedor: mulheres forçadas à submissão, serviçais vindos das colônias, trabalhadores acossados e crianças maltratadas formam um coro, silencioso e difuso, usualmente nas margens da trama, mas pleno de liames narrativos. Sua presença cria contrapontos e ilumina aspectos mais relevantes que os preconceitos e estereótipos articulados pelo narrador, em seu esforço para dirimir eventuais dissonâncias. Ao mesmo tempo, deve ser parte do empenho elucidativo na interpretação reconhecer que tais acomodações à ordem hegemônica não podem ser naturalizadas e vistas como um recurso estético entre outros. Em consequência disso, e como já apontado por Arnold Hauser, ${ }^{11}$ vale lembrar: o sentimentalismo dickensiano usualmente mascara uma aterradora crueldade, seu decoro está sempre a um passo da criminalidade e sua apologia da paz tem por hábito camuflar um acordo imposto pela violência - tudo isso, em consonância com as leis tácitas de sua época, matriz histórica de nosso próprio tempo.

${ }^{11}$ A. Hauser, História social da literatura e da arte, São Paulo, Martins Fontes, 2000. 